\title{
Издержки и выгоды корпоративной диверсификации
}

\author{
Шамраева C.A. ${ }^{14}$
}

Одним из важных решений, принимаемых менеджментом компаний, является решение относительно степени диверсификации бизнеса. Реализация стратегии диверсификации позволяет компаниям извлекать определенные выгоды, но в то же время сопряжена и с потенциальными издержками. С позиций теории корпоративных финансов эффективность прочесса диверсификаџии необходимо оченивать через ее влияние на стоимость компании. В статье представлено обсуждение основных факторов создания и разрушения стоимости диверсифицированными компаниями.

JEL: G30, G34, L25

Ключевые слова: корпоративная диверсификачия, стоимость компании, факторы стоимости, связанная диверсификация, несвязанная диверсификация

Диверсификация является одной из наиболее противоречивых стратегий развития бизнеса. Несмотря на то что большинство исследователей доказывают ее неэффективность, крупные диверсифицированные компании остаются преобладающей формой ведения бизнеса во многих странах. Сложность организации и функционирования диверсифицированной компании требует ее определения. Для этого выделим две группы признаков - организационно-управленческие и финансовые. Основными организационноуправленческими признаками диверсифицированной компании являются:

- наличие более чем одного направления деятельности, т.е. ведение операций сразу в нескольких отраслях экономики и существование нескольких бизнес-единиц, которые могут быть как связанными, так и несвязанными между собой по виду деятельности;

- наличие корпоративного центра (головной компании), который занимается формированием корпоративного бизнес-портфеля, принимает инвестиционные решения, осуществляет финансирование всей компании, в частности занимается распределением капитала между подразделениями, производит мониторинг и формирует отношения с внешней средой (государством, клиентами и т.д.);

- наличие многоуровневой организационной структуры и управленческой иерархии;

- наличие специальных знаний и навыков менеджмента, требуемых для ведения успешной конкурентной борьбы в конкретных видах деятельности;

- наличие навыков и компетенций, необходимых для управления несколькими бизнесами одновременно;

- $\quad$ наличие высоких издержек координации и контроля деятельности компании.

Указанные организационные особенности составляют основу для формирования набора финансовых характеристик, или характеристик, связанных с привлечением капитала и его размещением. К финансовым признакам, характеризующим внутреннюю финансовоинвестиционную среду компании, относятся:

- наличие внутреннего рынка капитала (internal capital market) [Liebeskind, 2000], что означает формирование в рамках диверсифицированной компании особого механизма перераспределения капитала между подразделениями и инструментария для осуществления контроля над их деятельностью. К таким инструментам относятся трансфертные внутрикорпоративные цены, устанавливаемые в зависимости от целей корпоративного центра, специфические условия кредитования и другие механизмы

\footnotetext{
${ }^{14}$ Преподаватель кафедры экономики и финансов фирмы ГУ ВШЭ, м.н.с. лаборатории корпоративных финансов.
} 
перемещения потоков денежных средств от одних бизнес-единиц к другим. Таким образом, вследствие диверсификации меняется поставщик капитала и происходит централизация инвестиционных решений, принятие которых основывается на субъективном мнении менеджмента корпоративного центра [Gertner, Scharfstein, Stein, 1994; Liebeskind, 2000];

- наличие «двухуровневого» агентского конфликта (two-tiered agency model) [Scharfstein, Stein, 2000].

Конфликтная природа отношений «агент (менеджмент) - принципал (собственник)» вытекает из объективного противоречия их интересов. Менеджмент компании ставит своей целью не максимизацию благосостояния акционеров, а реализацию собственных интересов, связанных с построением карьеры, увеличением собственной власти, статуса, обеспечения спокойной жизни и других различных привилегий [Jensen, Meckling, 1976; Jensen, 1986, 1993; Hart, Moore, 1995; Zwiebel, 1996; Constantinides, Harris, Stulz, 2003]. Устремления агента направлены на получение выгод в краткосрочной перспективе. Профессиональный успех должен быть капитализирован несколько раз за время работы в компании, поэтому достижение быстрых целей становится главной задачей менеджера. Интересы собственника направлены на получение результата от бизнеса в форме части денежных потоков, создаваемых в компании, либо от роста стоимости бизнеса через его продажу. Такие интересы основываются на продолжительном существовании компании, поэтому конфликт интересов неизбежен.

Существование нескольких уровней управления внутри диверсифицированной компании является предпосылкой для формирования дополнительного узла конфликтов типа «агент - агент», в котором корпоративный центр становится как бы «принципалом» по отношению к менеджменту (агенту) других уровней управления. Привлечение и перераспределение капитала в диверсифицированной компании осуществляется централизованно, через единственного поставщика капитала - корпоративный центр, обладающий полными, безусловными правами контроля над активами бизнес-единиц компании [Hart, Moore, 1990; Gertner, Scharfstein, Stein, 1994; Maksimovic, Phillips, 2007]. C одной стороны, рассматривая корпоративный центр как «принципала», можно предположить ужесточение с его стороны мониторинга при распределении капитала, что в свою очередь создает предпосылки принятия правильных с точки зрения создания стоимости решений. Но в тоже время обладание полными правами контроля снижает заинтересованность менеджеров-агентов в результатах их труда и ухудшает их предпринимательские стимулы, что ведет к снижению стоимости компании [Aghion, Tirole, 1997]. С другой стороны, менеджмент корпоративного центра сам, являясь агентом, заинтересован в извлечении собственных выгод от управления [Scharfstein, Stein, 2000]. Основываясь на этом, можно заключить, что многоуровневая структура диверсифицированных компаний способствует преумножению конфликтов интересов.

Как было отмечено выше, диверсификация может осуществляться путем вхождения в отрасли, связанные и несвязанные с основным бизнесом компании.

Под связанной диверсификацией понимается расширение видов деятельности при сохранении связи с основным бизнесом компании [Гохан, 2004; $\mathrm{OECD}^{15}$. При связанной диверсификации происходит совпадение звеньев цепочки создания стоимости, что позволяет компаниям обмениваться опытом, технологиями, совместно использовать бренды, маркетинговые каналы, снижать издержки и создавать иные конкурентно значимые преимущества [Sudarsanam, 2003; Стрикленд, 2009]. Согласно Маркидесу и Ульямсону, значение имеет прежде всего связанность (подобие) «стратегических активов» бизнесединиц компании, под которыми понимаются активы, лежащие в основе преимущества фирмы в затратах и дифференциации на определенном рынке и характеризующиеся

15 «Glossary of Industrial Organization Economics and Competition Law» http://www.oecd.org/dataoecd/8/61/2376087.pdf.

Выпуск \#2(14), 2010 С Электронный журнал Корпоративные Финансы, 2010 
невозможностью совершенной имитации, замещения и свободной продажи ${ }^{16}$. Наличие таких активов, их расширение и создание новых является основой долгосрочных конкурентных преимуществ связанной диверсификации [Маркидес, Уильямсон, 2008].

Несвязанная диверсификация представляет собой расширение видов деятельности без сохранения связи с основным бизнесом компании [Гохан, 2004, OECD].

В соответствии с теорией корпоративных финансов, достижение выгод от диверсификации должно рассматриваться в ракурсе роста стоимости компании. В основе этого роста во многом - достижение эффекта синергии. Синергия - это взаимодействие двух или более факторов, которые дают вместе больший эффект, чем сумма их независимых составляющих [Гохан, 2004; Рудык, Семенкова, 2000]. В области объединения компаний это ведет к приросту стоимости, созданному как результат умноженного эффекта.

Выделяют два типа синергии: операционную и финансовую [Дамодаран, 2004; Гохан, 2004; Grinblatt, Titman, 2002; DePamphilis, 2008].

Операционная синергия основана на комбинировании ресурсов, управленческих функций и стратегических способностей как общего типа, связанных с осуществлением функций стратегического и оперативного планирования и контроля, так и специфических функций, связанных с отраслевыми особенностями [Ивашковская, 2007].

Финансовая синергия основана на снижении инвестиционного риска и проявляется, главным образом, в снижении затрат на капитал объединенной компании.

Достижение операционной синергии характерно главным образом для связанной диверсификации. Данный вид синергии может проявляться в нескольких формах. Вопервых, в реализации различных видов экономий - на масштабе, охвате, разнообразии. Вовторых, в объединении различных сильных функциональных возможностей. Например, объединение компаний, у одной из которых сильная команда маркетинговых специалистов, а у другой - хорошая и пользующаяся популярностью продуктовая линейка. В-третьих, в преимуществе по ценообразованию, за счет сокращения конкуренции и увеличения доли рынка. В-четвертых, в возможностях быстрого роста на новом или существующем рынке, а также возможностях создания новых технологий и продуктов [Дамодаран, 2004]. Все это формирует потенциальные выгоды связанной диверсификации.

Однако данные преимущества могут быть существенно сокращены или полностью нивелированы характерными для данного вида объединений издержками. Основными факторами снижения стоимости компании, следующей стратегии связанной диверсификации, является невозможность расширения или создания «стратегических активов», ограниченный срок действия конкурентных преимуществ, заработанных на полученных в ходе интеграции различных экономиях, рассеивание контроля, сложности осуществления мониторинга, координации и коммуникаций в силу наличия нескольких уровней управления, а также высокие издержки реорганизации компании. Кроме того, чтобы суметь воспользоваться преимуществами стратегического соответствия, необходимо наличие соответствующих навыков и знаний у менеджмента для управления объединенной компанией, а также правильно выстроенная система управления. В большинстве эмпирических работ расширение в связанные отрасли оценивается в целом как более рациональное и эффективное по сравнению с экспансией в несвязанные сферы деятельности [Berger, Ofek, 1995, Claessens, Djankov, Fan, Lang, 2001; Fan, Goyal, 2006].

Диверсификация в совершенно несвязанные отрасли, конгломеративное расширение, является наиболее противоречивой стратегией развития компании с точки зрения ее влияния на стоимость. Поэтому ее анализу уделяется особое внимание.

Диверсификация часто сравнивается с диверсификацией портфеля инвестора. Вместо того чтобы покупать акции десяти различных компаний, действующих в разных отраслях, инвестор может купить одну акцию компании конгломерата, имеющего бизнесы в этих же

\footnotetext{
${ }^{16}$ Примером стратегического актива может служить дилерская сеть компании Ноnda, распространяющая и обслуживающая выпускаемые ею мотоциклы.
}

Выпуск \#2(14), 2010

(C) Электронный журнал Корпоративные Финансы, 2010 
отраслях. В данном случае предполагается, что конгломерат - это просто копия портфеля инвестора, и конгломеративная структура сама по себе не добавляет стоимости. Однако создание конгломерата - это не просто копия портфеля инвестора, а механизм использования возможных синергий и рыночного позиционирования [Sudarsanam, 2003]. В большей степени данная стратегия формирует условия для создания стоимости в результате достижения эффекта финансовой синергии [Grinblatt, Titman, 2002; DePamphilis, 2008]. Помимо этого, рост стоимости диверсифицированной компании определятся эффективностью функционирования внутреннего рынка капитала, решением агентских конфликтов, что в свою очередь во многом зависит от правильно выстроенной организационной структуры и грамотно поставленной системы управления компанией. На основе данных особенностей выделим три группы факторов стоимости диверсифицированной компании: экономические, финансовые и организационноуправленческие.

В первую очередь последовательно рассмотрим экономические факторы стоимости диверсифицированной компании, к которым относятся увеличение рыночной власти и эффективное использование ресурсов.

Диверсифицированные компании благодаря набору бизнес-направлений и размеру компании, могут устанавливать на рынке неконкурентное положение, направленное против существующих или потенциальных конкурентов, увеличивая тем самым свою рыночную власть. Данное преимущество диверсифицированных компаний было впервые изложено Эдвардсом в 1955 году [Edwards, 1955]

Можно выделить три возможных способа увеличения рыночной власти и установления неконкурентного положения на рынке:

- перекрестное субсидирование (cross-subsidizing);

- политика взаимного снисхождения (mutual forbearance);

- перекрестные закупки (reciprocal buying).

Одним из способов снижения конкуренции в отрасли является установление грабительских цен (predatory pricing) на продукцию по сравнению с конкурентами. Грабительское ценообразование предполагает назначение цены намного ниже средних издержек производства фирм конкурентного окружения [Авдашева, Розанова, 1998]. Финансирование данной стратегии осуществляется с помощью прибылей, получаемых на других направлениях бизнеса. Этот тип перекрестного субсидирования (cross-subsidizing) требует наличия значительных потоков денежных средств, которые в свою очередь могут быть получены благодаря размеру компании и набору бизнесов, которые она ведет.

В тех случаях, когда одни и те же компании конкурируют сразу на множестве рынков, может оказаться, что на некоторых из них их рыночные позиции меняются местами. В таких случаях они осознают свою взаимозависимость и могут применять политику «живи и дай жить другому». Компании-конкуренты, оперирующие только на одном рынке, не могут рассчитывать на подобное отношение и могут быть вытеснены. Оставшиеся фирмы, связанные политикой взаимного снисхождения (mutual forbearance), будут конкурировать между собой менее жестко.

От политики взаимного снисхождения конгломераты могут перейти к взаимной поддержке при помощи распределения между собой своих заказов (reciprocal buying). Конгломерат может одновременно выступать в роли заказчика другого конгломерата на одном рынке, и в роли поставщика на другом. В обоих случаях альтернативные поставщики будут исключены. Большая диверсификация на большем количестве рынков повышает шансы на взаимность. Принцип ведения дел от «живи и дай жить другому» меняется на «держись вместе и не давай проходу другим».

Авторы исследований, посвященных анализу рыночной власти диверсифицированных компаний, в целом подчеркивают, что увеличение власти является скорее следствием диверсификации, нежели ее причиной [Montgomery, 1994]. 
Несмотря на логичность этого подхода, эмпирические исследования нашли мало доказательств тому, что диверсификация дает компаниям конкурентные преимущества, поскольку позволяет им действовать нерыночными методами (демпинг и перекрестные закупки). Например, исследования диверсификации с точки зрения теории игр показывают, что демпинг эффективен не в каждой ситуации или может быть применим только лишь при определенных обстоятельствах. Эмпирические исследования случаев применения перекрестных закупок показали весьма противоречивые результаты [Palich, 2000; Bolton, Scharfstein, 1990].

В целом можно сказать, что такой фактор стоимости, как возможность увеличения рыночной власти, является далеко не определяющим при принятии компанией решения об экспансии в другие отрасли.

Целесообразность следования стратегии диверсификации можно объяснить с точки зрения эффективного использования ресурсов. В основе данного подхода лежит работа Пенроуз, опубликованная в 1959 году [Penrose, 1959]. Ресурсный подход предполагает, что компании стремятся диверсифицироваться вследствие наличия у них избыточных мощностей. Согласно Пенроуз, до тех пор, пока расширение деятельности способствует эффективному использованию незадействованных в производственном процессе ресурсов, компании имеют стимул к диверсификации.

Тис отмечает, что экономия на разнообразии, описанная Пенроуз, не может являться прямым стимулом для расширения компании, если только свободное перемещение избыточных ресурсов невозможно вследствие провалов рынка. В случае если излишние ресурсы компании могут быть достаточно эффективно проданы на открытом рынке, диверсификация бизнеса теряет свою актуальность [Теесе, 1980, 1982].

Монтгомери обращает внимание на то, что различные компании имеют и различный тип ресурсов. Чем менее специфическими ресурсами владеет компания, тем она может быть более диверсифицированной, и наоборот. Соответственно, тип ресурсов, которыми владеет компания, и определяет уровень оптимальной ее диверсифицированности [Montgomery, 1994].

Следующей группой факторов, которые могут повлиять при выборе стратегии расширения в пользу диверсификации, является возможность реализации финансовых преимуществ диверсификации, которые заключаются в использовании внутренних рынков капитала, налоговых выигрышей, снижения транзакционных издержек и в большей доступности к источникам заимствования.

Рассмотрение конгломерата как суррогата рыночного портфеля ценных бумаг предполагает, что инвестирование в портфель ценных бумаг сопряжено с большими транзакционными издержками, по сравнению с созданием диверсифицированной компании. На развитых рынках капитала транзакционные издержки формирования портфеля инвестора меньше издержек создания конгломерата. В этом случае инвестирование в конгломерат представляет собой достаточно дорогой способ диверсификации портфеля инвестора. В развивающихся странах, характеризующихся небольшим количеством компаний, котирующихся на бирже, ограниченным доступом на рынок иностранных инвесторов, высокой концентрацией собственности, компании, имеющие несколько бизнес-направлений, могут обеспечивать инвестору возможность диверсификации по разным отраслям и странам. В этой ситуации акции конгломеративных компаний, скорее всего, будут продаваться с премией [Brealey, Meyers, 2003; Дамодаран, 2004].

В качестве преимущества диверсификации компаний часто рассматривается возможность увеличения долговой способности интегрированной фирмы. Стратегия диверсификации позволяет распределять предпринимательский риск по различным отраслям, то есть инвестировать средства в несвязанные между собой отрасли с различными технологиями, условиями конкуренции, особенностями рынков, клиентской базой. Это является намного более безопасным, чем консолидация инвестиций в одной отрасли при связанной диверсификации. Исследование Любаткина и Чаттерджи показывает, что с 
финансовой точки зрения несвязанная диверсификация является более безопасной по сравнению с диверсификацией связанной [Lubatkin, Chatterjee, 1994].

Кроме того, диверсификация способствует снижению риска. Если денежные потоки подразделений не связаны друг с другом, то денежный поток компании будет более стабилен. Это означает большую защиту интересов кредиторов, так как снижается риск банкротства компании и повышает обеспеченность ее долговых обязательств. В результате снижаются затраты на привлекаемый капитал и увеличивается долговая способность компании.

Рассматривая рост способности заимствования как источник финансовой синергии, необходимо отметить, что в данном случае подразумевается, что до объединения обе компании имели оптимальный уровень долга. Если это не так, то возможность привлечения большего объема финансирования не следует рассматривать как синергию, так как каждая компания, действуя независимо, могла бы самостоятельно достичь оптимального уровня заемного капитала и увеличить свою стоимость.

Одной из форм налоговых выигрышей от диверсификации является так называемая компенсация налоговых платежей. Если одно из подразделений компании несет убытки, в то время как другое зарабатывает прибыль и платит значительные налоги, налогооблагаемая база единой компании может быть снижена. Стоимость синергии в данном случае представляет собой приведенную стоимость экономии на налогах. Другой формой налоговых экономий является рост амортизационных отчислений компании вследствие ее объединения и принятия на баланс несписанных активов компании-цели. Кроме того, в некоторых странах, например в Бразилии, после переоценки балансовой стоимости собственного капитала приобретенной компании часть этой стоимости, которая определяется законодательно, может быть рассмотрена как налоговый щит (аналогично расходам на выплату процентов) [Дамодаран, 2004].

Как было отмечено выше, одной из главных особенностей диверсифицированной компании является возможность организации и функционирования внутреннего рынка капитала. Внутренний рынок капитала - это механизм перемещения долгосрочных финансовых ресурсов от одного подразделения к другому в рамках диверсифицированной компании [Liebeskind, 2000]. Эффективность функционирования данного рынка капитала во многом определяет и эффективность диверсифицированной компании с точки зрения создания стоимости.

На сегодняшний день не существует единого взгляда на проблему внутреннего рынка капитала. Согласно Вильямсон, данные рынки распределяют ресурсы внутри компании более эффективно, нежели это делают внешние рынки капитала [Williamson, 1975]. Гертнер, Шарфштайн и Штайн отмечают, что внутренние рынки капитала предоставляют лучшие возможности мониторинга и перегруппировки активов по сравнению с внешними [Gertner, Scharfstein, Stein, 1997]. Штайн утверждает, что распределение капитала материнской компанией создает стоимость и ограничивает искажения, которые могут возникать в связи с издержками привлечения внешнего финансирования [Stein, 1997]. Однако другая группа исследователей выступает за неэффективность внутреннего рынка капитала. Согласно Раджану, Серваесу и Зингалесу, в случае когда подразделения диверсифицированной компании имеют различные инвестиционные возможности, менеджмент корпоративного центра может направлять поток финансовых средств из бюджета капиталовложений от крупных подразделений с хорошими инвестиционными возможностями к подразделениям с низкими инвестиционными возможностями, осуществляя так называемую политику «социалистического» перекрестного субсидирования [Rajan, Servaes, Zingales, 2000]. Данные выводы также нашли свое подтверждение в ряде других исследований [Shin, Stulz, 1998; Scharfstein, 1998; Billet, Mauer, 2003]. С точки зрения Готье и Хейдер (2002), Индерст и Ло (2005), Бруско, Панунци (2005), даже при условии эффективного распределения ресурсов между подразделениями диверсифицированной компании создаются условия для роста 
агентских издержек, что ведет к разрушению стоимости интегрированной фирмы [Gautier, Heider, 2009; Inderst, Laux, 2005; Brusco, Panunzi, 2005].

Эффективность внутренних рынков может во многом определяться состоянием экономики в целом. Данные рынки способствуют росту стоимости компании в условиях недостаточно зрелых внешних рынков капитала, слабой правовой среды, информационной закрытости [Stein, 2003]. В условиях развивающихся экономик внутренние рынки капитала формируют дополнительные источники создания стоимости, так как могут заменять функции и инструменты недостаточно развитых внешних рынков.

Таким образом, механизм внутреннего рынка может рассматриваться как фактор создания, так и как фактор разрушения стоимости диверсифицированной компании, а это во многом может зависеть от состояния институциональной среды, в которой функционирует фирма.

Диверсифицированные компании, как было показано выше, имеют определенный потенциал эффективности. Портфель бизнесов может вести к созданию эффекта как операционной, так и финансовой синергии, механизмы внутреннего рынка капитала позволяют привлекать значительные объемы финансирования и рационально распределять полученные ресурсы. Для реализации отмеченного потенциала необходимо, чтобы менеджмент компании был заинтересован в ее управлении таким образом, чтобы стало возможным превратить указанные преимущества компании в факторы создания ее стоимости. Это представляется достаточно сложной задачей, поскольку интересы менеджмента направлены прежде всего на удовлетворение собственных амбиций и потребностей. Стратегия диверсификации является выгодной для менеджмента по нескольким причинам. Во-первых, рост размеров компании способствует извлечению менеджментом частых выгод от контроля; во-вторых, позволяет менеджменту прочно закрепить за собой свое рабочее место, «окопаться» [Shleifer, Vishny, 1989]; в-третьих, дает возможность менеджменту диверсифицировать риск собственного портфеля; в-четвертых, сложная организационная структура компании способствует искажению информационных потоков, что ведет к асимметрии информации и создает благоприятную почву для удовлетворения личных интересов менеджмента бизнес-единиц [Sharfstein, Stein, 2000].

Анализируя эмпирические исследования, можно сделать вывод о том, что диверсификация оказывает скорее положительное влияние на вознаграждения менеджмента, которые могут проявляться как в увеличении денежных компенсаций, так и в увеличении различных привилегий [Khorana, Zenner, 1998; Girma, Thompson, Wright, 2002].

Существование агентского конфликта следует рассматривать как фактор снижения стоимости диверсифицированной компании. Сложная иерархия контроля и управления такой компанией из-за большого количества бизнес-подразделений требует налаживания внутренних механизмов сглаживания агентских конфликтов. К таким механизмам прежде всего относятся системы компенсации топ-менеджерам, членам совета директоров, менеджерам среднего и низшего звена, а также организация надлежащего корпоративного управления. Пока система поощрений и стимулирование не соответствует корпоративным целям, пока компания не следует должным образом принципам корпоративного управления, информационный поток внутри нее будет подвержен манипулированию для удовлетворения требований менеджеров разных уровней, а не для удовлетворения требований корпорации в целом. Эта потеря контроля является издержками размера и диверсифицированности компании.

Перейдем к рассмотрению организационно-управленческих факторов стоимости диверсифицированной компании. С точки зрения теории жизненного цикла любая компания проходит несколько этапов в своем развитии. На различных этапах жизненного цикла меняются организационные характеристики компании, поэтому на разных стадиях организации требуются различные методы управления. Организационно-управленческая специфика компании создает возможности получения выгод от объединения нескольких 
видов бизнеса, предопределяет финансовые отношения внутри диверсифицированных компаний, а также выступает самостоятельным фактором стоимости компании.

Во-первых, при диверсификации бизнеса очень важно определить его масштабы, то есть количество бизнес-единиц, входящих в корпоративный портфель. В связи с этим менеджмент должен четко представлять, сколькими подразделениями он сможет эффективно управлять. Необходимо установить минимальный и максимальный уровень диверсификации: первый определяется показателями прибыльности и роста, второй возможностями эффективного управления. Во-вторых, организация и функционирование диверсифицированных компаний сопряжены с высокими издержками координации и контроля. Если эти издержки превышают выгоды от диверсификации, то стоимость компании будет снижаться. В-третьих, диверсифицированные компании не всегда могут быть эффективными по некоторым причинам, таким как наличие асимметрии информации, затрудняющей процесс мониторинга; неэффективность системы мотивации; наличие агентской проблемы и неэффективность распределения ресурсов, что препятствует приведению целей подразделений компании в соответствие с общей корпоративной целью максимизации стоимости. В-четвертых, построение инновационной организационной формы деятельности компании, направленной на нивелирование неэффективности ее функционирования, будет способствовать эффективному распределению капитала и росту стоимости компании в целом. Согласно исследованию Бетель, Либескинд, организационноправовая форма диверсифицированной компании оказывает влияние на ее стоимость. Выводы их исследования говорят о том, что наиболее разумной с точки зрения создания стоимости является организация диверсифицированной компании в виде корпоративного центра и подконтрольных ему бизнес-единиц (corporate group). Но в то же время такая организация может приводить к снижению возможностей экономии на масштабе, поскольку координация деятельности внутри группы компаний затруднена; поэтому при принятии решения о создании бизнес-групп необходимо принимать во внимание возможные потери от экономии на масштабе [Bethel, Liebeskind, 1998)]. В более раннем исследовании Рамельта в качестве наиболее подходящей формы организации бизнеса диверсифицированной компании рассматривается М-форма (multidivisional) ${ }^{17}$ [Rumelt, 1982]. Однако стоит отметить, что способы организации и функционирования диверсифицированных компаний во многом зависят от законодательства той или иной страны, ее культуры и развития.

Помимо рассмотренных факторов создания и разрушения стоимости компаниями, придерживающимися стратегии несвязанной диверсификации, необходимо сделать акцент на еще одном существенном факторе, о котором частично упоминалось выше, - степени развитости институциональной среды страны, в рамках которой функционирует диверсифицированная компания. Согласно теории транзакционных издержек [Coase, 1937; Williamson, 1985], оптимальная структура компании зависит от состояния институциональной среды. При неразвитости последней особую актуальность приобретают диверсифицированные компании, которые могут брать на себя функции различных институтов развитого рынка, тем самым создавая потенциал увеличения стоимости для объединенных компаний [Khanna, Palepu, 1997, 2000]. Слабость институциональной среды накладывает значительные ограничения на функционирование специализированных компаний, ставя их существование под угрозу. Такие компании могут извлекать выгоды, действуя в рамках диверсифицированных объединений или бизнес-групп, которые являются наиболее распространенной формой организации бизнеса на развивающихся рынках капитала. Однако с другой стороны жесткие ограничения таких рынков в большей степени способствуют возникновению агентских издержек, связанных с диверсификацией. Высокий уровень асимметрии информации открывает для менеджмента компаний и мажоритарных

17 Для стратегии связанной диверсификации организационная структура СМ-формы является более эффективной, чем М-форма. СМ-форма (centralized multidivisional) представляет собой мультидивизиональную фирму, в которой корпоративный центр принимает участие в операционном управлении подразделениями [Маркидес, Уильямсон, 2008]. 
акционеров возможности для извлечения собственных выгод от диверсификации, что в свою очередь может приводить к потере стоимости диверсифицированными компаниями. Таким образом, развитость рынка капитала, на котором ведет деятельность диверсифицированная компания, также может выступать как фактором создания, так и фактором разрушения стоимости диверсифицированной компании.

Выявив и рассмотрев основные выгоды и издержки диверсификации, на следующем этапе выясним еще один важный вопрос: какие факторы являются преобладающими в деятельности реальных компаний, т.е. какое влияние оказывает диверсификация на стоимость компании? Исследованию этого вопроса посвящено большое количество эмпирических работ, построенных на данных компаний как развитых, так и развивающихся рынков капитала. Обзор исследований можно увидеть в работах И.В.Ивашковской, С.А.Шамраевой, Е.Е. Григориади [2009, С.А. Григорьевой [2007], Н.Б. Рудыка [2005]. Следует отметить, что консенсус относительно эффектов диверсификации в финансовоэкономической литературе до сих пор не найден. В то время как одни исследователи доказывают разрушение стоимости в результате следования стратегии диверсификации, другие показывают ее эффективность. Это говорит о том, что процесс исследования последствий диверсификации далек от завершения. Продолжают появляться новые работы, которые затрагивают не рассмотренные ранее аспекты, используют новые данные и модифицированные методы.

\section{Список литературы}

1. Авдашева С.Б., Розанова Н.М. Теория организации отраслевых рынков. М.: Магистр, 1998.

2. Дамодаран А. Инвестиционная оценка. Инструменты и методы оценки любых активов. М.: Альпина Бизнес Букс, 2004.

3. Гохан П. Слияния, поглощения и реструктуризация компаний. М.: Альпина Бизнес Букс, 2004.

4. Григорьева С.А. Финансовые исследования стратегий диверсификации на развитых и растущих рынках капитала // Корпоративные финансы. 2007. № 1. С. 111-144.

5. Ивашковская И.В., Шамраева С.А., Григориади Е.Е. Эмпирический анализ эффективности корпоративной диверсификации на растущих рынках капитала на примере группы BRIC // Экономический журнал ВШЭ. 2009. № 3. С. 360-382.

6. Корпоративные финансы. Руководство к изучению курса / под ред. И.В. Ивашковской М.: Издательский дом ГУ-ВШЭ, 2007.

7. Маркидес К.С., Уильямсон П. Дж. Связанная диверсификация, ключевые компетенции и результаты корпорации // Российский журнал менеджмента. 2008. № 6(1). С. 65-88.

8. Рудык Н.Б. Конгломеративные слияния и поглощения. Книга о пользе и вреде непрофильных активов. М.: Дело, 2005.

9. Рудык Н.Б., Семенкова Е.В. Рынок корпоративного контроля: слияния, жесткие поглощения и выкуп долговым финансированием. М.: Финансы и статистика, 2000.

10. Стрикленд Дж., Томпсон А. Стратегический менеджмент. Концепции и ситуации для анализа. 12-е издание. Москва, Санкт-Петербург, Киев: Вильямс, 2009.

11. Aghion, P., Tirole, J. (1997), Formal and real authority in organizations, Journal of Political Economy, 105 (1997) 1-29.

12. Berger, P.G., Ofek, E. (1995), Diversification's effect on firm value, Journal of Financial Economics, 37 (1995) 39-65.

13. Bethel, J., Liebeskind, J.P. (1998), Diversification and the Legal Organization of thr Firm, Organization Science, 9(1) (1998) 49-65. 
14. Billett, T.M., Mauer, D.C. (2003), Cross-Subsidies, External Financing Constraints, and the Contribution of the Internal Capital Market to Firm Value, The Review of Financial Studies, 16(4) (2003) 1167-1201.

15. Bolton, P., Scharfstein, D.S. (1990), A theory of predation based on agency problems in financial contracting, American Economic Review, 80 (1990) 93-106.

16. Brealey, R., Myers, S. (2002), Principles of Corporate Finance. - The MvGraw-Hill Companies.

17. Brusco, S., Panunzi, F. (2005), Reallocation of Corporate Resources and Managerial Incentives in Internal Capital Markets, European Economic Review, 49(3) (2005) 659-681.

18. Claessen, S., Djankov, S., Fan, J., Lang, L. (2001), The Pattern and Valuation Effects of Corporate diversification: A Comparison of the US, Japan, and Other East Asian Economies, World institute for development economics research, Discussion paper. 127 (2001).

19. Coase, R. (1937), The Nature of the Firm // Economica. 1937. 4 (1937) 386-405. URL: http://www.sciencedirect.com.

20. Constantinides, G.M., Harris, M., Stulz. R. (2003), Handbook of the economics of finance. - Corporate Finance Elsevier B.V.

21. DePamphilis, D.M. (2008), Mergers, Acquisitions, and Other Restructuring Activities. Elsevier.

22. Edwards, C.D. (1955), Conglomerate bigness as source of power. In National Bureau Committee for Economic Research, Business concentration and price policy. - Princeton: Princeton University Press.

23. Fan, J.P.H., Goyal, V.K. (2006), On the patterns and wealth of vertical mergers, Journal of Business, 79(2) (2006) 877-902.

24. Gautier, A., Heider, F. (2009), The Benefit and Cost of Winner-picking: Redistribution vs. Incentives, Journal of Institutional and Theoretical Economics, 165 (2009) 622-649.

25. Gertner, R.H., Scharfstein, D.S., Stein, J.C. (1994), Internal versus external capital markets, Quarterly Journal of Economics, 109 (1994) 1211-1230.

26. Girma, S., Thompson, S., Wright, P. (2002), Multinational Activity and CEO Compensation: Preliminary Evidence from Large UK Firms, Review of World Economics, 138 (2002) 680-693.

27. Grinblatt, M., Titman, S. (2002), Financial Markets and Corporate Strategy. - The McGraw-Hill Companies.

28. Handbook of Corporate Finance / Edited by Eckbo B.E. (2007) in: Maksimovic V., Phillips G. Conglomerate Firms and Internal Capital Markets. Elsevier, p. 423-479.

29. Hart, O., Moore, J. (1995), Debt and seniority: an analysis of the role of hard claims in constraining management, American Economic Review, 85 (1995) 567-585.

30. Inderst, R., Laux, C. (2005), Incentives in Internal Capital Markets: Capital Constraints, Competition, and Investment Opportunities, RAND Journal of Economics, 36 (1) (2005) 215-228.

31. Jensen, M.C., Meckling, W.H. (1976), Theory of the Firm: Managerial Behavior, Agency Costs, and Ownership structure, Journal of Financial Economics, 3 (1976) 305-360.

32. Jensen, M.C. (1986), Agency costs of free cash flow, corporate finance, and takeovers, American Economic Review, 76 (1986) 323-329.

33. Jensen, M.C. (1993), The modern industrial revolution, exit, and the failure of internal control systems, Journal of Finance, 48 (1993) 831-880.

34. Khanna, T., Palepu, K. (1997), Why Focused Strategies May Be Wrong for Emerging Markets, Harvard Business Review, July-August (1997) 41-51.

35. Khanna, T., Palepu, K. (2000,) Is Group Affiliation Profitable in Emerging Markets? An Analysis of Diversified Indian Business Groups, The Journal of Finance. LV(2) (2000) 867-889. 
36. Khorana, A., Zenner, M. (1998), Executive Compensation of Large Acquirers in the 1980s, Journal of Corporate Finance, 4 (1998) 209-240.

37. Liebeskind, J.P. (2000), Internal Capital Markets: Benefits, Costs, and Organizational Arrangements, Organization Science, 11(1) (2000) 58-76.

38. Lubatkin, M., Chatterjee, S. (1994), Extending modern portfolio theory into the domain of corporate diversification: does it apply? Academy of Management Journal, February (1994) $109-136$.

39. Montgomery, C.A. (1994), Corporate Diversification, Journal of Economic Perspective, 8(3) (1994) 163-178.

40. Palich, L.E., Cardinal, L.B., Miller, C.C. (2000), Curvilinearity in the diversificationperformance linkage: An examination of over three decades of research, Strategic Management Journal, 21 (2000) 155-174.

41. Penrose, E. (1959), The Theory of the Firm. - Oxford: Basil Blackwell.

42. Rajan, R., Servaes, H., Zingales, L. (2000), The cost of diversity: the diversification discount and inefficient investment, Journal of Finance, LV(1) (2000) 35-80.

43. Rumelt, R.P. (1982), Diversification strategy and profitability, Strategic Management Journal, 3 (1982) 359-370.

44. Schleifer, A., Vishny, R. (1989), Management entrenchment: the case of manager specific investments, Journal of Financial Economics, 25 (1989) 123-139.

45. Sharfstein, D. (1998), The dark side of internal capital markets II: Evidence from diversified conglomerates, NBER Working paper 6352.

46. Sharfstein, D.S., Stein, J.C. (2000), The dark side of internal capital markets: divisional rent-seeking and inefficient investment, Journal of Finance, LV(6) (2000) 2537-2564.

47. Shin, H., Stulz, R. (1998), Are internal capital markets efficient? Quarterly Journal of Economics, 113 (1998) 531-552.

48. Stein, J.C. (1997), Internal capital markets and the competition for corporate resources, Journal of Finance, 52 (1997) 111-133.

49. Stein, J. (2003), Agency, Information and Corporate Investment. Handbook of the Economics of Finance. - Elsevier Science B.V.

50. Sudarsanam, S. (2003), Creating value from mergers and acquisitions: the challenges, an international and integrated perspective. - FT Prentice Hall.

51. Teece, D. (1980), Economics of Scope and the Scope of the Enterprise, Journal of Economic Behavior and Organization, I (1980) 223-247.

52. Williamson, O. (1975), Markets and Hierarchies, Analysis and Antitrust Implications: a Study in the Economics of Internal Organization. - New York: Free Press.

53. Zwiebel, J. (1996), Dynamic capital structure under management entrenchment, American Economic Review, 86 (1996) 1197-1215. 